\title{
Survey of 105 Villages in the Livingstone District, Northern Rhodesia.
}

W

HEN in Livingstone, Northern Rhodesia, I visited a few villages in company with Mr. Farquhar B. Macrae and demonstrated a rough method of leprosy survey. Mr. Macrae, when on tour of the villages in his district, continued the survey on the lines I had indicated, and this note is published in the hope that those who are on "safari" will be stimulated to take an interest in leprosy. Leprosy lends itself to rapid surveys of this kind, and in the average village of Africa it is not difficult to collect the villagers together and examine them for leprosy. The people are generally not opposed to such examinations, and 
as they can generally recognise leprosy it is a fairly easy matter to divide up cases into the types here indicated.

It is seen in this survey that out of a population of $7,741,101$ suffered from leprosy, giving an incidence of 1.3 per cent. As it has been generally held that there is very little leprosy in and around Livingstone, such a percentage is rather startling. If, however, the figures are examined it will be seen that out of 101 cases only four are in the highly contagious stage and 13 (raised patches) are presumably in the mildly infective stage That is 17 per cent. are open cases and 83 per cent. are closed. This is suggestive that while the incidence of leprosy is fairly high yet the type is not so severe. It would be interesting to discover whether in a known leprous area these percentages would be reversed. The point is that while an incidence of 1 per cent. is high, yet an area where 83 per cent. are closed cases is not so dangerous from the public health point of view, as one where open cases were over 50 per cent. Further, if these 83 cases were largely adults the assumption is that the community in this area is highly resistant. If the percentage of open cases was high, and the majority of early cases were children or adolescents then the disease should be actively combated, for it would be suggested that the population had a low resistance to the disease.

These few remarks I trust will stimulate Medical Officers, Missionaries and others to study and investigate leprosy along such lines. Such figures for an area of supposedly low incidence are rather surprising and one is constrained to ask, if these are the rough figures for the district around Livingstone, what would they be if known heavily infected areas such as Basutoland were thus surveyed. The following table is a summary of the statistics furnished by Mr. Macrae :-

\begin{tabular}{|c|c|c|c|c|c|c|c|}
\hline 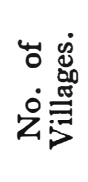 & 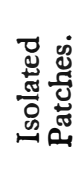 & 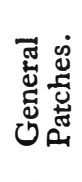 & 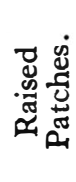 & 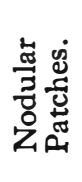 & & $\begin{array}{l}\dot{\pi} \\
\dot{0}\end{array}$ & 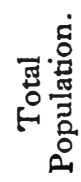 \\
\hline 105 & 25 & 11 & 13 & 4 & 48 & 101 & 7,741 \\
\hline
\end{tabular}

EDITOR. 